\title{
Managing supply chain integration: contemporary approaches and scope for further research
}

The fundamental value of supply chain management for business improvement is widely acknowledged in the literature. Increasingly, organisations are looking for effective ways to manage the supply chain. Supply chain integration $(\mathrm{SCl})$ is one of the major challenges in enhancing supply chain performance (in terms of cost, quality, flexibility and time performance). Building and sustaining competitive advantage requires strategic collaboration between supply chain partners and synchronised management of intra- and inter-organisational practices and processes (Yeung et al. 2009, Flynn et al. 2010). SCl therefore refers to coordination mechanisms in terms of business pro- cesses that should be interrelated within and beyond company boundaries (Romano 2003). The integration of supply chain management systems has been the subject of significant debate and discussion (Power 2005). Recently, a number of articles on $\mathrm{SCl}$ have appeared in leading academic journals (including more questions than answers. This special issue attempts to address some of the fundamental $\mathrm{SCl}$ questions, which include but are not limited to the fields of organisational collaboration, information technology (IT) use, risk and vulnerability manage- ment, inventory management, performance measure- ment and management control, relationship management and green practices. The editorial first reviews a few key articles on $\mathrm{SCl}$ in order to shed light on the current state of knowledge on $\mathrm{SCl}$ along with scope for further research. It then introduces the articles that are selected for this special issue. This editorial concludes with a note on further scope of research on $\mathrm{SCl}$.

Collaboration, in the context of the supply chain, is still relatively new as it is difficult to implement effectively, due to over-reliance on technology, diffi- culty in identifying the right partners and lack of trust (Barratt 2004). Barratt and Oliveira (2001) find that a major barrier to collaborative planning, forecasting and replenishment is a lack of attention to developing front-end agreements, especially on what organisations will collaborate on. Another major barrier would appear to be the context for collaboration, in terms of when to collaborate and with whom. For authors such as Thrane and Hald (2006), one of the most significant factors is buyer-side leadership, which is proven to be an important antecedent for supply chain collaboration. Although authors like Barratt (2004) have identified a significant number of elements of collaboration, however, it is as yet unclear how these elements interrelate. Therefore, further research is also required to develop a deeper understanding of the relationships between these elements of collaboration.

Evidence has shown that vendor-managed inven- tory (VMI) can improve supply chain performance by decreasing inventory levels and increasing fill rate (Emigh 1999). Although Yao et al. (2007) present an analytical model for VMI that gives benefit to both suppliers and customers, many assumptions limit its application to certain circumstances. Therefore, future work could look at developing a more robust model, with consideration of both the strategic and the operational needs of the firm.

Definitions of $\mathrm{SCl}$ range from 'cross-functional process integration within the firm' to 'complete forward and backward supply chain integration'. Coordination among functions is a crucial antecedent to effective supply chain interaction. Early adopters of supply chain practice have discovered that real collaboration goes beyond information exchange; they are working diligently to establish other integra- tive mechanisms to enhance coordination with impor- tant first-tier suppliers and customers (Fawcett and Magnam 2002).

There is growing evidence linking SCl to perfor- mance improvement (Zailani and Rajagopal 2005). The importance of $\mathrm{SCl}$ for performance enhancement is emphasised by academics who have studied manu- facturing companies in different countries (Kim 2006, Mahama 2006, Welker et al. 2008, Wong and Boon-Itt 2008, Kim 2009, Jayaram et al. 2011). Droge et al. (2004) state that the extent of external as well as internal integration processes and practices impacts positively on flexibility factors, including product development time, product cycle time and delivery time.

The need to address market changes through SCl cannot be ignored. Narasimhan and Kim (2002) examine the effect of $\mathrm{SCl}$ on the relationship between diversification and a firm's competitive performance. Their study is useful in integrating supply chain strategy into market and product diversification strategy. However, further research is 
required into the effect of contextual variables on the interaction of diversification, $\mathrm{SCl}$ and organisational performance.

Donk and Vaart (2005) introduce a framework that demonstrates which business conditions determine integrative practices. They find that dealing with uncertainty through lead-time management and shar-ing resources improves integration. However, the higher level of uncertainties in both specification and volume make close cooperation and integration more important, though hard to achieve in cases of shared resources. Donk and Vaart point out that research on the level of performance associated with different levels of integration is needed.

Digital platforms play a critical role in managing supply chain activities and partnerships that improve supply chain performance. Gunasekaran and Ngai (2004) review the application of IT in supply chain management and its impact on SCl. Rai et al. (2006) reveal that integrated IT infrastructures enable firms to develop the higher order capability of supply chain process integration. They further point out that more research is needed to explore the relationship between physical, financial and information flow, and their impact on organisational performance.

Business process modelling using simulation helps achieve $\mathrm{SCl}$ through the renovation of every aspect of the processes and effective information sharing (Trkman et al. 2007). Childerhouse and Towill (2003) show that material flow holds the key to $\mathrm{SCl}$. The study reveals that reduced material flow time through the supply chain, appropriate production planning, lead-time compression, just-in-time production, adopt- ing group technology, reduction of uncertainties, visible information flow across the supply chain, use of a robust decision support system and having a unifying goal for all the stakeholders reduces uncer- tainties and results in increased SCl.

Although many European firms have adopted ERP systems to link their supply chain partners, a major problem is that these systems generally support internal coordination across functional activities, but are less supportive in decision-making across organisa- tional boundaries (Bagchi et al. 2005). SCl is more a rhetoric than a reality in most industries in Europe. While performance has been shown to have improved as a result of collaboration with suppliers and customers alike in areas, such as supply chain design, inventory management and customer relationship management, the nature and extent of integration have been rather selective. Whereas many studies have advanced the virtues of inventory transparency and sharing of strategic manufacturing plans across the supply chain for better decision-making, the ground realities are quite different. Most companies are quite cautious when it comes to sharing sensitive data. Very few companies have established joint decision-making with their key suppliers or customers (Bagchi et al. 2005). These authors found, through a survey, that there is a significant correlation between the length of relationship with suppliers and performance measures such as total logistic costs, on-time delivery and rate of return.

Furthermore, our concise state of the art shows an increasing interest in analysing the deployment of management control and performance measurement systems (PMSs) contributing to the integration of supply chains. For example, Mahama (2006) high- lighted direct relationships between PMSs and three dimensions of cooperation: information sharing, pro- blem solving and willingness to adapt to changes. Indeed, PMSs can serve as information systems and as media for performance accountability (Abernethy and Lillis 2001). Thrane and Hald (2006) demonstrated that performance measurement and control systems served to integrate entities that were internal and external to the focal firm as well as to fragment the firm. The non-satisfaction stemming from mainstream perspectives on performance measurement of the customer-supplier relationship is due to their suffering from a lack of alignment with organisational logics and structures and to their producing diffuse and non- integrated knowledge. In addition, while many com- panies are adopting PMSs to monitor their partner- ships, there is much empirical evidence that highlights their shortcomings in terms of adaptability and consistency (Kamminga and Van der Meer-Kooistra 2007, Vosselman and Van der Meer-Kooistra 2009).

Taking into consideration the current state of the art on $\mathrm{SCl}$, this special issue extends the knowledge on $\mathrm{SCl}$ through 13 research articles, selected from more than 40 submissions. This special issue emphasises a comprehensive approach that states that both cross- functional integration within a firm and external integration with suppliers or 
customers are needed for successful supply chain management. This issue collates empirical research as well as reviewing the works of authors from Europe, Canada, South East Asia, the Middle East and Australia. The articles adopt multiple-criteria decision-making approaches, fuzzy theory, statistical analysis, content analysis, grounded theory and other methods to analyse their data and so draw their conclusions.

Alfalla-Luque, Medina-Lopez and Schrage propose an innovative SCI model using three robust constructs (information integration, coordination and resource sharing, and organisational relationship linkage) and apply this to the aeronautical industry. The model enables the authors to determine the level of integra- tion, to identify where there is room for improvement and to suggest specific improvement measures. Ganotakis, Hsieh and Love investigate whether cross- functional integration within a firm and the use of IT systems that support information sharing with external parties can enhance integration across the supply chain and wider networks. Additionally, they analyse the effect of collaboration with customers, suppliers and other external parties on supply chain performance for new product development and the introduction of new processes. Baihaqi and Sohal, through empirical study, demonstrate the impact on organisational performance of information sharing in the supply chain. The study reveals that information sharing does not directly relate to organisational performance. Nagati and Rebolledo demonstrate how to improve operational performance through knowledge exchange with custo- mers. Their conceptual model is tested using a sample of 218 Canadian manufacturers; the results reveal that the exchange of tacit and explicit knowledge with customers enhances the supplier's operational performance.

Effective risk management helps integrate the supply chain. Bhattacharyya, Geraghty and Young present a resilient 'shock absorber' for a distributed supply chain network. This facilitates the assessment of the resilience strategies of supply chain networks that are prone to 'excursion events'. This strengthening framework also enables practitioners to identify and assess quantitatively the 'excursion events' in the supply chain network. Vlajic, Lokven, Haijema and Vorst present a supply chain vulnerability assessment model that analyses organisational performance when supply chain disturbance occurs. This additionally helps organisations to decide whether their current process is appropriate or should be redesigned in order to increase the robustness of the supply chain. The proposed method has been applied to a meat supply chain using discrete-event simulation to demonstrate its effectiveness.

Effective inventory management helps integrate both upstream suppliers and downstream customers. Jemai, Rekik and Kalaiï discuss a VMI and vehicle- routing decision model to improve global performance of the supply chain. They consider this model in the context of supplier integration and present quantitative evidence that transshipment permits organisations to optimise distribution and to improve the global performance of the supply network. Abdlaziz and Mejri introduce an innovative decentralised bilevel model for shared inventory management using the fuzziness of some parameters due to the available information being imprecise. They have applied the proposed model to a large corporation that owns a warehouse and two concurrent chains. The warehouse is looking into minimising its inventory cost and at the same time reducing personnel turnover.

Developing the relationship with suppliers and maintaining it on a long-term basis is one of the most challenging tasks in supply chain management. Sharma presents a model for developing the supplier relationship through categorising suppliers with respect to cost of production along with other cost criteria.

Enterprise governance contributes to integrating today's supply chain. Clegg, Chandler, Binder and Edwards introduce collaborative enterprise governance (CEG) concepts to manage technology projects. Using grounded theory, they have applied the proposed CEG concepts to Jaguar Land Rover, a UK-based car manufacturer and leader in research and development management.

Climate change issues and environmental manage- ment are major challenges to any organisation today. Integrated supply chain management emphasises green operations, green supply chain performance measure- ment, carbon footprint calculation across the supply chain and so on, in order to achieve efficiency and responsiveness. This special issue covers this through two articles - green supply chain performance mea- surement framework and modelling a low carbon supply chain. Dey and Cheffi present a multiple- criteria decision-based framework for 
measuring green supply chain performance and apply it to three manufacturing organisations in the UK. Their framework provides an effective way to measure and benchmark companies' relative performance in green supply chains. Shaw, Shankar, Yadav and Thakur's article introduces a mathematical model to determine and optimise the cost and carbon emission of manufacturing processes. They have applied the model to a garment-manufacturing company to demonstrate its effectiveness.

Alfalla-Luque, Medina-Lopez and Dey present a literature review on $\mathrm{SCl}$ using supply chain manage- ment and operations management literature for the period 1995-2009. The study reveals that information integration, coordination and resource sharing, and organisational relationship linkage are three major dimensions for $\mathrm{SCl}$. These dimensions help integrate both upstream suppliers and downstream customers with the focal organisation. It also enables $\mathrm{SCl}$ to be measured using both qualitative and quantitative approaches.

The $\mathrm{SCl}$ methods and approaches need maturity in terms of linking each construct for achieving superior performance; there is therefore a need for further empirical research to develop theories on $\mathrm{SCl}$. The SCl methods and approaches require maturity in terms of linking each construct for achieving superior perfor- mance. On the one hand, the role of technology for integration needs to be researched further and on the other hand, whether building relationship across supply chain stakeholders helps develop integration needs to be revealed. Additionally, synergy between supply chain performance and integration requires evidence based analysis.

\section{References}

Abernethy, M.A. and Lillis, A.M., 2001. Interdependencies in organization design: a test in hospitals. Journal of Management Accounting Research, 13, 107-129.

Bagchi, P.K., et al., 2005. Supply chain integration: a European survey. The International Journal of Logistics Management, 16 (2), $275-294$.

Barratt, M., 2004. Understanding the meaning of collabora- tion in the supply chain. Supply Chain Management: An International Journal, 9 (1), $30-42$.

Barratt, M. and Oliveira, A., 2001. Exploring the experiences of collaborative planning: the enablers and inhibitors. International Journal of Physical Distribution \& Logistics Management, 31 (2), 266-289.

Childerhouse, P. and Towill, D.R., 2003. Simplified material flow holds the key to supply chain integration. Omega, 31 (1), 17-27.

Donk, D.P.V. and Vaart, T.V.D, 2005. A case of shared resources, uncertainty and supply chain integration in the process industry. International Journal of Production Economics, 96, 97-108.

Droge, C., Jayaram, J., and Vickery, S.K., 2004. The effects of internal versus external integration practices on time- based performance and overall firm performance. Journal of Operations Management, 22, 557-573.

Emigh, J., 1999. Vendor-managed inventory. Computerworld, 33 (34), 52.

Fawcett, S.E. and Magnam, G.M., 2002. The rhetoric and reality of supply chain integration. International Journal of Physical Distribution \& Logistics Management, 32 (5), 339-361.

Flynn, B.B., Huo, B., and Zhao, X., 2010. The impact of supply chain integration on performance: a contingency and configuration approach. Journal of Operations Management, 28, 58-71.

Gunasekaran, A. and Ngai, E.W.T., 2004. Information system in supply chain integration and management. European Journal of Operational Research, 159, 269-295.

Jayaram, J., Xu, K., and Nicolae, M., 2011. The direct and contingency effects of supplier coordination and customer coordination on quality and flexibility performance. International Journal of Production Research, 49 (1), 59-85.

Kamminga, P.E. and Van der Meer-Kooistra, J., 2007. Management control patterns in joint venture relation- ships: a model and an exploratory study. Accounting Organization and Society, 32 (1-2), 135-158.

Kim, S.W., 2006. The effect of supply chain integration on the alignment between corporate competitive capability and supply chain operational capability. International Journal of Operations and Production Management,26 (10), 1084-1107. 
Kim, S.W., 2009. An investigation on the direct and indirect effect of supply chain integration on firm performance. International Journal of Production Economics, 119, 328-346.

Mahama, H., 2006. Management control systems, coopera- tion and performance in strategic supply relationships: a survey in the mines. Management Accounting Research, 17, 315-339.

Narasimhan, R. and Kim, S.W., 2002. Effect of supply chain integration on the relationship between diversification and performance: evidence from Japanese and Korean firms. Journal of Operations Management, 20, 303-323.

Power, D., 2005. Supply chain management integration and implementation: a literature review. Supply Chain Management: An International Journal, $10(4), 252-263$.

Rai, A., Patnayakuni, R., and Seth, N., 2006. Firm perfor- mance impacts of digitally enabled supply chain integration capabilities. MIS Quarterly, 30 (2), 225-246.

Romano, P., 2003. Coordination and integration mechanisms to manage logistic processes across supply networks. Journal of Purchasing and Supply Management, 9, 119-134.

Thrane, S. and Hald, K.S., 2006. The emergence of bound- aries and accounting in supply fields: the dynamics of integration and fragmentation. Management Accounting Research, 17, 288-314.

Trkman, P., et al., 2007. Process approach to supply chain integration. Supply Chain Management: An International Journal, 12 (2), $116-128$.

Vosselman, E.G.J. and Van der Meer-Kooistra, J., 2009. Accounting for control and trust building in interfirm transactional relationships. Accounting, Organizations and Society, 34 (2), 267-283.

Welker, G.A., Van der Vaart, T., and Van Donk, D.P., 2008. The influence of business conditions on supply chain information-sharing mechanisms: a study among supply chain links of SMEs. International Journal of Production Economics, 113 (2), 706-720.

Wong, C.Y. and Boon-Itt, S., 2008. The influence of institutional norms and environmental uncertainty on supply chain integration in the Thai automotive industry. International Journal of Production Economics, 115 (2), 400-410.

Yao, Y., Evers, P.T., and Dresner, M.E., 2007. Supply chain integration in vendor-managed inventory. Decision Support Systems, 43, 663-674.

Yeung, J.H.Y., et al., 2009. The effect of trust and coercive power on supplier integration. International Journal of Production Economics, 120 (1), 68-78.

Zailani, S. and Rajagopal, P., 2005. Supply chain integration and performance: US versus East Asian companies. Supply Chain Management: An International Journal, 10 (5), 379-393. 